\title{
The breeder reactor: a fossil fuel viewpoint
}

\author{
David Merrick considers what economic and technical \\ factors would make the fast breeder reactor a viable option
}

\begin{abstract}
THE concept of the fast breeder re$T_{\text {actor is elegant and simple: to gener- }}$ ate electricity and, at the same time, to produce additional fuel from the uranium discarded by the existing thermal reactor system. Without the breeder reactor, it seems likely that the role of nuclear energy will begin to be constrained by the price and availability of uranium at about the turn of the century. There is, however, no consensus on the desirable, or even possible, contribution of breeder reactors to future energy supplies. Foremost among the uncertainties discussed in the current debate are the questions of safety and environmental impact. Assuming concern in these areas can be satisfactorily and economically resolved, there still remain questions on the technical and economic limitations of the use of breeder reactors.
\end{abstract}

\section{Performance of the breeder system} In making the case for the breeder reactor, the most commonly quoted index of performance is that $30 \%$ to $60 \%$ of the energy available in the uranium fuel can be liberated, compared with about $1 \%$ in most thermal reactors. The exact value of the efficiency depends on the plutonium losses in reprocessing, the $60 \%$ figure being valid only if these can be limited to $2 \%$.

In addition to approximately 4 tonnes of plutonium in the core, a $1 \mathrm{MW}$ breeder reactor contains about 50 tonnes of depleted uranium in the core and blanket. This is converted by the reactor to plutonium (and other elements) and typically, a further 50 tonnes of depleted uranium are required as replacement during a lifetime's operation. A single breeder reactor will, therefore, utilise only $15 \%$ to $30 \%$ of the uranium required for its operation, if the initial charge is included.

The uranium inventory can be considered as a form of storage and remains useful provided there is a continuing programme of breeder reactor construction. If, however, an expanding programme of breeder capacity is planned, a further constraint, the availability of fissile material for the reactor core, is encountered. Although it would be technically possible to use highly

The author is at the Coal Research Establishment near Cheltenham. enriched uranium for this purpose, to do so would be costly, and the reactor performance, although improving slowly during the lifetime of the plant, would not initially be in the 'breeding' regime $^{1}$. For these reasons the design of breeder reactors, and scenarios for their introduction (for example the United Kingdom Atomic Energy Authority's 1974-75 evidence to the Royal Commission on Environmental Pollution ${ }^{2}$, concentrate on the use of plutonium as the fissile material.

It is expected that the Liquid Metal Fast Breeder Reactor (LMFBR) will breed $20 \%-25 \%$ more plutonium than is required as fuel. This excess plutonium can be used as inventory for further breeder reactors. A crucial parameter affecting the strategy for the introduction of breeder reactors is the doubling time, that is, the time taken for a breeder reactor to produce sufficient plutonium to provide the initial fuel charge for another similar reactor. The doubling time depends not only on the breeding gain of the reactor itself, but also on the delay time and losses in reprocessing the partially burned fuel. At the present state of reactor and reprocessing technology, the doubling time would be more than 50 years ${ }^{3}$, although this is expected to be cut to a period in the range 25 to 40 years for commercial reactor systems (at a $70 \%$ load factor). As neither the reactor nor the reprocessing plant are likely to be demonstrated on a commercial scale for several years, it seems prudent to assume a mid-range value of, say, 33 years for planning purposes.

It is claimed that further reductions in the doubling time could be obtained by using carbide instead of oxide fuel, or a gas-cooled reactor instead of the present liquid metal designs. However, even the achievement of a 33-year doubling time in an acceptable commercial system will entail a substantial development programme, and whether sufficient incentive would then remain to embark on further such programmes is not clear.

At the beginning of a programme of breeder reactor construction, the plutonium required for the reactor core would be obtained as a by-product of the thermal reactor programme. In most situations, the available stocks of plutonium would be rapidly exhausted, and the rate of construction of breeder reactors would then be limited by the rate at which plutonium becomes available from existing thermal and breeder reactors. In the UK, for example, stocks of separated plutonium would, at present, enable $1 \mathrm{GW}$ of breeder capacity to be built ${ }^{2}$. This should rise to about $7 \mathrm{GW}$ in 1985 .

Whether the breeder programme can ever become independent of the thermal reactor programme depends on the growth rate of the nuclear electricity system, and the doubling time. At a doubling time of 33 years, plutonium production from the breeder reactor system can only sustain a growth rate of around $3 \%$ per annum. For the growth rate of the nuclear electricity system to be greater than $3 \%$ per annum, it is necessary to construct both thermal and breeder reactors.

In this situation, the efficiency with which uranium is utilised by the overall system of breeder and supporting thermal reactors is considerably lower than the value of $60 \%$ claimed for the breeder reactor alone. This is illustrated in Fig. 1, which shows the uranium utilisation for the system of breeder (LMFBR) and supporting thermal reactors (PWR) at various growth rates. Also shown, for comparison, is the uranium utilisation if the CANDU thermal reactor, with plutonium recycle, were to be used. This system performs better than the LMFBR/PWR system at growth rates above about $5 \%$ per annum.

If, therefore, a rapid build-up of nuclear capacity were desirable, the LMFBR/PWR system would, during the period of growth, offer a relatively small improvement in uranium utilisation over the PWR, and little or no improvement over the CANDU system. Only if the projected plutonium doubling time of commercial breeder reactor systems were to be substantially reduced could a high growth rate in breeder capacity be achieved, but there is no evidence at present that this would be technically or economically possible.

\section{Growth of the breeder system}

Besides limiting the overall efficiency of uranium utilisation in the nuclear reactor system, the availability of plutonium for the cores of breeder reactors

Table 1 Estimated uranium import requirements 2000-2020 AD

\begin{tabular}{|c|c|c|c|}
\hline $\begin{array}{l}\text { Growth } \\
\text { rate } \\
(\% \text { per } \\
\text { annum) }\end{array}$ & $\begin{array}{c}\text { LWR } \\
+ \\
\text { LMFBR }\end{array}$ & $\begin{array}{c}\text { LWR } \\
+ \text { Pu } \\
\text { recycle }\end{array}$ & $\begin{array}{c}\text { CANDU } \\
\text { recyucle }\end{array}$ \\
\hline $\begin{array}{l}1 \\
3 \\
5\end{array}$ & $\begin{array}{r}39,000 \\
76,000 \\
220,000\end{array}$ & $\begin{array}{l}105,000 \\
214,000 \\
433,000\end{array}$ & $\begin{array}{r}51,000 \\
103,000 \\
208,000\end{array}$ \\
\hline
\end{tabular}


also acts as a constraint on the rate at which breeder capacity can be introduced. This can be illustrated by considering an idealised situation in which the commissioning of new power stations precisely matches the steadily growing level of demand. The maximum rate of introduction of breeder reactors is shown in Fig. 2 if, at year zero, new power station construction is suddenly switched from fossil fuel to nuclear.

At annual growth rates in electricity demand below $3 \%$, breeder reactors can eventually account for all nuclear power generation, although to achieve this takes at least 50 years. At higher growth rates, the ultimate contribution of breeders is limited, as discussed above.

For a given electrical output thermal reactors generally produce plutonium at least as quickly as breeders. If the introduction of breeders is delayed, plutonium stocks can, therefore, be built up, enabling breeder capacity to increase rapidly once the breeder programme begins. Even a delay of 30 years does not significantly affect the time required for the breeder to reach the maximum possible contribution, as shown in Fig. 2.

Forecasts of the rate of growth of breeder reactor capacity and the impact of uranium imports to the UK are complicated by the present over-capacity of power stations and the plutonium stocks from existing stations. Approximate estimates of uranium requirements in the first 20 years of next century are given in Table 1, assuming that an early decision to go ahead with a demonstration-scale breeder reactor is made. This would enable the first orders for commercial plants to be made by the middle/late 1980 s for commissioning in 1995.

The introduction of breeder reactors will, on this timescale, only reduce uranium consumption to just under half of the requirements of a nuclear programme based on the PWR alone and will show little advantage over the CANDU thermal reactor. The choice of thermal reactor system can, therefore, have a similar impact on uranium requirements to the breeder on this timescale, and cannot be divorced from the decision to pursue breeder technology. The sixty-fold improvement in uranium utilisation frequency claimed for the breeder will not be realised for the system as a whole until well into next century. Although the mediumterm savings will be worthwhile provided uranium prices are high, breeder technology cannot ensure a secure, indigenous supply of energy, effectively insulating the UK from the expense of high cost uranium, for more than half a century.
Economics of breeder reactor systems

Although it has been claimed that the capital cost of fast breeder power stations need not be greater than that of thermal stations, it now seems likely that, even if there are no major technical difficulties, the cost will be at least $25 \%$ more than that of a PWR. In order to be economically viable, this additional capital investment must be paid for by the lower fuel costs. At present, the cost of uranium ore accounts for less than $10 \%$ of the total generation cost so that, other factors being equal, a substantial increase in the price of uranium would be necessary to justify the extra capital cost of a breeder reactor.

This is confirmed by a more detailed analysis, which shows that the approximate cost of uranium ore needed for a breeder to produce electricity as cheaply as a thermal reactor is directly proportional to the additional capital cost of the breeder. (The plutonium produced by the breeder and thermal reactors is credited with its value as a supplementary fuel in thermal reactors, although in the case of the breeder this credit is more than offset-at a $10 \%$ discount rate-by the cost of the initial charge of plutonium.) Although this analysis is necessarily approximate, such a relationship means that the FBR is unlikely to give visible economic benefits until uranium prices have increased to $\$ 100-\$ 200$ per pound of $\mathrm{U}_{3} \mathrm{O}_{8}$. This represents an increase in real terms of three to six times.

The rate at which uranium prices will move upwards depends on the future growth of world nuclear capacity and reserves and discoveries of high grade uranium ores. Neither of these can be estimated with any certainty and no consensus of opinion exists on the earliest date at which this consideration would be decisive in favour of the breeder. The UKAEA anticipates that uranium prices will increase to $\$ 100-\$ 200$ a pound when all the high grade ores are committed to existing nuclear programmes in the 1990 s, and conclude that breeder capacity should be built up as quickly as possible. The Central Electricity Generating Board (CEGB), however, takes the view that the main justification for the FBR is in reducing requirements for uranium in the long term, as resources may be limited, rather than on economic grounds.

In order for nuclear energy to remain competitive for base load power generation duty at uranium prices in the range $\$ 100$ to $\$ 200$ a pound, fossil fuel prices would have to rise by between $50 \%$ and $100 \%$ relative to power station construction costs. Although, in the UK, power station coal now costs about $2 \frac{1}{2}$ times as much as it did three years ago (an increase even allowing

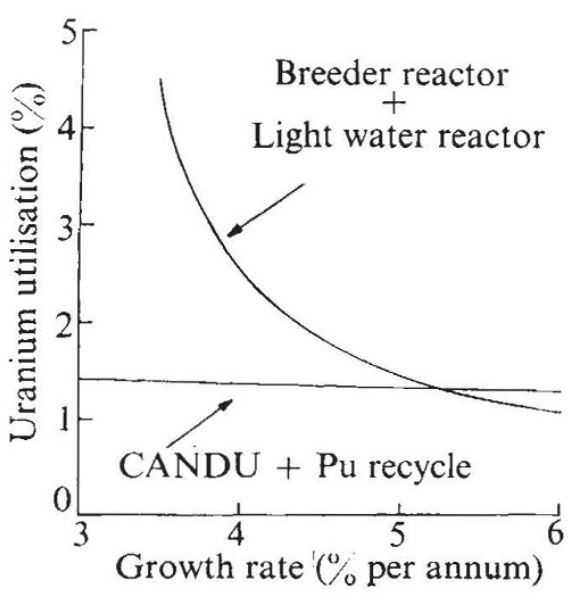

Fig. 1 Uranium utilisation in a steadily expanding system.

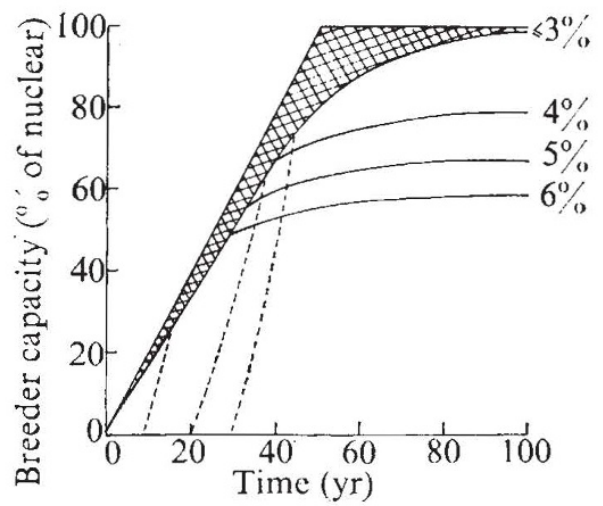

Fig. 2 Rate of growth of breeder capacity in an idealised system assuming various annual growth rates for electricity demand. For the $3 \%$ annual growth curve, the effects of delaying introduction of the fast breeder by 10,20 and 30 years are shown by dashed lines.

for inflation), power station construction costs have risen by a similar amount over the same period, leaving the relativities in power generation costs not greatly different.

There is clearly a possibility that the increased cost of nuclear power generation brought about by high uranium prices will either reduce the competitiveness of nuclear electricity compared with other forms of energy or, should the price of the alternatives also increase, inhibit economic growth and consequently energy demand. In either case, the assumption of a continued high rate of growth in nuclear capacity after high grade uranium ores are exhausted appears open to question.

\section{Fossil fuels}

The justification for the breeder is essentially long term. No clear economic advantage is likely until uranium prices have risen three to six times above their present level. Furthermore, the contribution of a breeder/LWR system to reducing uranium requirements is unlikely to exceed that of an 
efficient thermal reactor system until well into the next century.

If demand continues to grow so that it becomes impracticable to rely on thermal reactors, fossil fuels, and renewable resources for power generation, the breeder reactor would have an important contribution to make. It is against this scenario that the development of breeder technology could be considered a valuable assurance of adequate electricity supplies.

After the turn of the century, it is expected that crude oil and natural gas production will begin to decline. This, because of the unique advantages of fossil fuels, will encourage substitution either directly or indirectly, by coal. For that to occur most efficiently, new technologies for the combustion of coal and its conversion into substitute hydrocarbon fuels are required.

The development of coal conversion processes and breeder technology have certain similarities. In both cases, the construction of demonstration scale plants will soon be required. The earliest times by which each technology need be applied in the UK are similar, although both could, if required, be introduced before they become economic in order to forestall sudden increases in energy prices. Once the technology has been demonstrated, however, the rate of commercial exploitation of coal conversion processes is not limited as for the fast breeder reactor, and a significant impact on energy supplies should be possible in a comparatively short period of time. Furthermore, the UK is already in a strong position on coal technology and the export potential of coal conversion processes should be no less than that of breeder technology.

The size of the relative contributions of breeder technology and coal conversion processes depends on whether electricity will continue to penetrate the energy market as prices increase. It is probable that substitute fuels from coal will be most effective competitors for nuclear electricity in the heating market. The estimated capital cost per unit of energy output of, for example, a plant to convert coal to substitute natural gas is about one third that of a nuclear power station, and the thermal efficiency is approximately double. Furthermore, the low load factors associated with the heating demand do not affect the economics of coal conversion as much as electricity generation. The use of nuclear energy for other than electricity generation does not look attractive at present, and would require considerable technical problems to be solved.
In conclusion, breeder reactors are capable of making a substantial contribution to energy supplies by using the uranium rejected from the thermal reactor programme. The availability of plutonium is likely to limit the rate at which breeder reactors can be built for several decades. If a vigorous development programme enabled breeder reactors to be introduced commercially by the 1990 s, even although they would probably not be economic by this date, they would be unable to insulate the UK effectively from the need for expensive uranium imports until well into next century. The need to develop and demonstrate breeder technology can therefore be compared with the development of other medium-term energy options. Coal conversion processes, in particular, will be required to play a vital role in this timescale and merit no less attention and priority than breeder technology.

I thank Mr L. Grainger, National Coal Board Member for Scienre, for guidance and encnurngement, and the NCB for heln with the vrenaration of this article. The views exnressed are, however my own and not necessarily those of the NCB.

'Leslie, D. C., Aspects of Energy Conversion (edit. by Blair, I. M., Jones, B. D., and Van Horn, A. J.) (Pergamon, Oxford, 1976).

Royal Commission on Environmental Pollution Sixth Report: Nuclear Power and the Environmen (HMSO, London, 1976).

3 Vaughan, R. D., and Farmer, A. A., Proc. Instn

4 CEGB Corporate Plan 1976 (CEGB, London, 1976).

\section{Dolphin dissonance}

\section{Colin Norman reports from Washington on the threat that tuna fishing poses for dolphins}

$\mathrm{N}$ the past 15 years, between 5 and 6 million dolphins are believed to have drowned in the nets of tuna fishermen. The slaughter of these highly intelligent, friendly mammals has sparked one of the most bitter and complex conservation battles ever waged in the United States. A number of environmental groups, backed to some extent by the federal government, are fighting to protect the animals, while the tuna industry, according to its spokesmen, is fighting for its own survival. The battle is now focused on regulations, due to take effect in January, which conservationists say are vitally needed to protect the dolphin schools, but which the tuna industry claims will put the United States tuna fleet out of business.

The dolphin owes its plight to the fact that, for unexplained reasons, some species frequently swim with yellowfin tuna-a type of tuna which is in high demand and which fetches the highest prices. Because the airbreathing dolphins swim on the surface, they have for decades provided tuna fishermen with a convenient guide to the location of schools of yellowfin. Until the late 1950s, tuna fishing was mostly done by hook and line, and the dolphins lost nothing by showing fishermen the way to yellowfin schools. But a technological innovation in the industry rapidly changed all that.

The innovation was the development of a massive net, called a purse seine, which tuna fishermen spread around dolphin schools and then draw in to land the yellowfin beneath the dolphins. It is a very effective way to catch tuna, but the problem is that dolphins frequently become entangled in the nets and, when they can't get to the surface to breathe, they drown. During the $1960 \mathrm{~s}$, an average of about 400,000 dolphins a year were dying in tuna nets; since they have no commercial value, they were thrown overboard.

Because the dolphin schools play a valuable role in leading tuna boats to yellowfin, it is in the fishermen's interest to try to preserve the animals by reducing the slaughter. They began to experiment with various manouevres and changes to the nets in the 1960s, but the killing continued virtually unabated until 1972. At that point, Congress stepped in.

\section{Public concern}

Public concern over the killing of marine mammals had been aroused by the plight of many species of whales, which had been hunted virtually to extinction, and the needless slaughter of dolphins by tuna fishermen consequently became an emotionally charged issue in the early 1970 s. Congress responded to the concern by passing the Marine Mammal Protection Act (MMPA) in 1972.

A compromise between the argument that the tuna industry would be wiped out by a total ban on the killing of dolphins, and the need to protect the animals, the act essentially gave the industry a two-year grace period. By October 1974, the act said, the killing of dolphins by purse seiners must be reduced to "insignificant levels approaching zero".

Congress had been led to believe that such a requirement could be met. During testimony before a House committee in 1971, Joe Medina, a tuna boat captain, reported that trials with a modified purse seine had reduced the kill of dolphin in a 'set' to insignificant amounts. "This now net has been a 